\title{
Locomoção Independente: contribuição aos programas de orientação e mobilidade
}

\section{Visually Impaired People's Locomotion: contribution to mobility and orientation process}

\begin{abstract}
Resumo: A bengala usada pelos cegos na locomoção funciona como extensão do sentido tátil, no entanto, não atende à necessidade de leitura de elementos localizados acima da linha da cintura, comumente encontrados nos centros urbanos, e que se configuram como barreiras físicas. Essas barreiras, tal como telefones públicos, toldos, lixeiras e outros, podem ocasionar acidentes, transmitindo insegurança na locomoção. Este artigo descreve o projeto Bengala Longa Eletrônica, o qual foi desenvolvido com o intuito de auxiliar no processo de Orientação e Mobilidade do cego em espaços urbanos. A nova bengala possui uma eletrônica embarcada que sinaliza a presença de obstáculos através de vibrações e sons. Para avaliar a técnica desenvolvida foi estruturado um experimento com situações comumente encontradas pelos cegos durante o seu deslocamento, em interiores e em espaços abertos. Os resultados alcançados mostram a relevância do equipamento de Tecnologia Assistiva desenvolvido, ressaltando sua contribuição aos programas de Orientação e Mobilidade.
\end{abstract}

Palavras-chave: Acessibilidade. Tecnologia Assistiva. Bengala Longa. Orientação e Mobilidade. Deficiência Visual.

Abstract: The long cane widely used by blind people in their daily locomotion works as an extension of tactile sense, however, it does not supply the need to read elements located above the waistline, which are commonly found in urban centers and represents physical barriers. Those barriers, such as pay phones, awnings, dumps and others may cause accidents, transmitting insecurity. This paper describes the Assistive Technology project Electronic Long Cane, which had been developed as a mobility aid for blind or visual impaired people in open urban spaces. The approach comprises an ergonomic design along with an embedded electronics located inside the grip of a traditional cane. The device, by mean of haptics, warns about obstacles above waistline avoiding potential collisions, so leading to a better surrounding perception and safer locomotion. An experiment and the related evaluation were carried out by voluntary blind people showing a relevant contribution to Mobility and Orientation programs.

Keywords: Accessibility. Assistive Technology. Long Cane. Mobility and Orientation. Visual Impairment.

SILVA, Renato Fonseca Livramento da; RAMIREZ, Alejandro Rafael Garcia. Locomoção Independente: contribuição aos programas de orientação e mobilidade. I nformática na Educação: teoria e prática, Porto Alegre, v. 15, n. 2, p. 183-197, jul./dez. 2012.

\section{Renato Fonseca Livramento da Silva \\ Universidade da Paraíba}

\author{
Alejandro Rafael Garcia Ramirez
}

Universidade do Vale do Itajaí

\section{I ntrodução}

$\mathbf{P}$ erceber o espaço implica de algum modo vivenciá-lo, e em se tratando de pessoas portadoras de necessidades especiais, essa experiência necessariamente deve ser proporcionada da maneira mais segura e adequada às características e necessidades de cada indivíduo. Portanto, todos os esforços para o aprimoramento do processo de interação com o meio urbano são oportunos. Nesse sentido a legislação brasileira manifesta o empenho a favor das pessoas portadoras de deficiência de modo que seja efetivamente posta em prática em seu benefício, garantindo-lhes a proteção e o amparo devidos, facilitando a locomoção e o aceso ao mercado de trabalho.

Nesse contexto, o design industrial constitui uma ferramenta importante, em função 
da consistência de suas metodologias que, em geral, são caracterizadas por abordagens focadas na identificação das necessidades inerentes a cada demanda (ou problema) de projeto e buscam o profundo entendimento das particularidades de cada caso.

Um fator relevante do design industrial é a possibilidade de adotar uma abordagem inclusiva, que naturalmente objetiva viabilizar projetos voltados a assegurar o uso de produtos - mesmo aqueles que representam soluções particularizadas - pelo maior número possível de pessoas que deles necessitem. Conciliam-se a essa proposta as tecnologias desenvolvidas para espaços urbanos, direcionadas para atender às pessoas portadoras de deficiência visual. Elas geralmente assumem o caráter de soluções integradas e procuram ampliar as possibilidades de interação com a complexidade do espaço que a cerca, proporcionando, com isso, melhorias significativas na sua qualidade de vida.

Por outro lado, os programas de ensino de Orientação e Mobilidade, através de suas técnicas, ajudam aos portadores de deficiência visual a vivenciar ativamente os espaços urbanos e, para tanto, passam necessariamente por um processo que depende no primeiro momento da superação das dificuldades associadas à falta de visão. Posteriormente, a família e às pessoas próximas delas assumem um importante papel.

De acordo com Felippe e Felippe (1997, p. 8), “[...] a maioria dos deficientes visuais, por um determinado tempo, convive com os efeitos de perda nos aspectos físico, psíquico, social e econômico, que exigem reorganização e estabelecimento de novos esquemas de interação [...]". Sem essa reorganização, fica comprometida qualquer iniciativa que obje- tive auxiliá-los no seu processo de integração social. Nessa perspectiva, a possibilidade de locomoção independente, principalmente no espaço urbano, surge como um fator importante na vida do cego. O processo de aprendizado da locomoção independente dessas pessoas, na maioria dos casos, passa necessariamente pelo ensino de Orientação e Mobilidade que, por sua vez, possui como elemento-chave, o equipamento de Tecnologia Assistiva bengala longa.

Os argumentos até aqui apresentados demonstram a relevância do presente estudo. Este trabalho soma-se aos esforços para garantir de forma continuada a implantação dos critérios de acessibilidade na configuração das cidades e visa contribuir para o fornecimento de informações sobre o espaço urbano aberto e o processo de percepção, orientação e deslocamento durante o uso desses espaços, em particular. Importante sustentação da proposta é oferecida por Dischinger e Ely, ao considerarem que

[...] um dos campos de pesquisa mais avançados na busca de soluções para melhorar a acessibilidade aos espaços públicos urbanos para portadores de deficiência visual é o desenho de instrumentos que permitam a obtenção de informações espaciais por meios não visuais. (DISCHI NGER; ELY, 1999, p. 1)

Nesse sentido, ganham relevância os estudos que possam colaborar com deficientes visuais na percepção e no gerenciamento das informações referentes aos espaços urbanos, aumentando dessa forma as possibilidades de inclusão social e melhoria da qualidade de vida das pessoas que possuem algum tipo restrição, seja ela circunstancial ou permanente. 
Os objetivos deste artigo são apresentar o projeto de Tecnologia Assistiva Bengala Longa Eletrônica e analisar suas contribuições relacionadas ao deslocamento em centros urbanos de forma independente. Com essa finalidade foi estruturado um experimento com situações comumente encontradas pelos cegos, durante o seu deslocamento, em interiores e em espaços urbanos abertos, fazendo uso do equipamento desenvolvido e sendo analisada a eficácia no referente ao fornecimento de informações em relação à presença de barreiras físicas localizadas acima da linha da cintura. Os resultados alcançados mostram a relevância do equipamento de Tecnologia Assistiva Bengala Longa Eletrônica, ressaltando sua contribuição nos programas de Orientação e Mobilidade.

\section{Orientação e Mobilidade}

Para melhor compreensão do projeto desenvolvido, julga-se necessário entender a importância do ensino da Orientação e Mobilidade para pessoas portadoras de deficiência visual, assim como, a característica formal e de uso da bengala longa desenvolvida pelo médico estadunidense Dr. Richard Hoover, principalmente considerando o fato do projeto Bengala Longa Eletrônica, não alterar significativamente a configuração da bengala longa tradicional, cuja técnica de uso, especificamente a de toque, foi utilizada nos experimentos desta pesquisa.

De acordo com Garcia (2003) em 1950, após estudos relacionados à problemática da cegueira e a mecânica da marcha, o Dr. Richard Hoover desenvolveu uma bengala mais longa e mais leve que as tradicionais de apoio, para ser utilizada como uma extensão do dedo indicador, e assim sondar através da percepção tátil-cinestésica, o espaço à frente, detectando a natureza e condições do piso, existência de obstáculos, depressões, aclives, declives, localização de pontos de referência e também proteger aparte inferior do corpo de colisões. Dessa forma, teve início o programa de Orientação e Mobilidade estruturado.

O processo de Orientação e Mobilidade, de acordo com Hoffmann e Seewald (2003), é comumente confundido pelas pessoas com a aprendizagem apenas do uso da bengala longa, mas na realidade, tal processo envolve diversas outras estratégias e recursos que auxiliam na locomoção. De acordo com os autores a Orientação e Mobilidade pode ser entendida como um processo amplo e flexível, composto por um conjunto de capacidades motoras, cognitivas, afetivas e sociais e por um elenco de técnicas apropriadas e específicas que permitem ao seu usuário conhecer, relacionar-se e deslocar-se de forma segura, independente e natural nas mais diversas estruturas, espaços e situações do ambiente.

Para a Sociedade de Assistência aos Cegos (SAC) Orientação e Mobilidade “[...] é a área da educação especial voltada à educação e a reabilitação de pessoas portadoras de deficiência visual, seja por problemas congênitos ou adquiridos [...]" (SAC, 2010). De acordo com a referida associação o programa de treinamento é dividido em várias etapas, que inicialmente ocorrem em ambientes internos das instituições, e onde são trabalhados aspectos fundamentais, tais como cognitivos, psicomotores e emocionais, assim como o treinamento dos sentidos remanescentes. I mporta salientar que as estratégias e recur- 
sos mais utilizados no processo de Orientação e Mobilidade para deficientes visuais são, de acordo com Felippe (2001, p. 6): “[ ...] a autoproteção, o guia humano, a bengala longa, o cão-guia e, mais recentemente, as ajudas eletrônicas [...]".

Felippe (2001, p. 4) estabelece que “[...] o ensino de Orientação e Mobilidade é fundamental para a interação do indivíduo com o ambiente [...]". Pode-se afirmar baseado no que o autor coloca, que o seu domínio através de suas técnicas e recursos, juntamente com a adoção de critérios de acessibilidade nos espaços e produtos, se constitui em ações que alargam as possibilidades de autonomia do cego, constituindo-se também, num dos caminhos para a sua independência, sobretudo, quando nos referimos ao seu processo de interação com espaço urbano, geralmente complexo e dinâmico.

Torna-se importante destacar que a Orientação e Mobilidade, para as pessoas que são portadoras de algum tipo de deficiência visual, de acordo com Garcia (2003, p. 68) “[...] ocorre como qualquer indivíduo, desde o nascimento. O que vai caracterizar a diferença são as necessidades dessas pessoas, que devem ser estimuladas, o mais cedo possível, através dos seus sentidos remanescentes [...]".

Sobre a inicialização do uso da bengala longa Hoffmann e Seewald (2003) colocam que suas técnicas, podem ser introduzidas na vida de uma criança, adolescente ou adulto de maneira formal ou informal, dentro de brincadeiras ou atividades pedagógicas específicas, uma vez que nem sempre estes indivíduos estão motora e emocionalmente preparados para o seu uso. Os autores colocam que muitas vezes, uma criança necessita de um instrumento que ainda não deve possuir as características formais da bengala longa utilizada pelo adolescente ou pelo adulto, pois precisa de uma base de sustentação maior do que a proporcionada pela bengala longa. Em outras situações, o fato da pessoa se deparar com buracos, árvores e outros obstáculos, pode fazer com que ela desista de utilizar a bengala longa se ela não estiver bem estimulada, estruturada emocionalmente e com domínio das técnicas da Orientação e Mobilidade, porque a frustração e o constrangimento gerados pelas colisões, intromissões e situações imprevistas são fatores que os deixam confusos, inseguros e desmotivados para seguir com o aprendizado.

Antes de iniciar o programa específico de Orientação e Mobilidade, de acordo com Garcia (2003, p. 68), o professor deverá observar e avaliar de forma sistemática as habilidades e as limitações do aluno para planejar programas que levem à formação de conceitos e, a saber, o momento exato de iniciar tal programa e de que forma serão introduzidas as técnicas específicas de mobilidade.

Dentro do ensino de Orientação e Mobilidade a bengala longa ou de Hoover como também é conhecida, assume grande importância no processo de deslocamento independente dos deficientes visuais, sobretudo em espaços urbanos abertos. Assim, parte integrante dos programas de ensino em Orientação e Mobilidade é constituída pela bengala longa. De acordo com Hoffmann e Seewald,

[...] a bengala não tem uma função ortopédica ou de sustentação, mas de proteção, orientação e detecção das informações ambientais captadas por sensações táteis e percebidas pelos receptores localizados na mão do indivíduo cego, sendo enviadas ao seu cérebro. Portanto, a bengala longa tem a função de aumentar o alcance da perna e do braço de um indivíduo cego [...]. (HOFFMANN; SEEWALD, 2003) 
O treinamento no uso das técnicas específicas da bengala longa pressupõe o treinamento na utilização de todos os sentidos remanescentes e deve ser ensinado necessariamente por um instrutor ou professor especializado em suas técnicas.

\section{Equipamento de Tecnologia Assis- tiva Bengala Longa}

A bengala longa, comumente utilizada pelos deficientes visuais, se caracteriza por sua leveza e seus tamanhos mais alongados, em relação aos bastões, mais curtos e pesados que comumente utilizavam-se antes da proposta de Hoover. A bengala longa configurase em três partes distintas, como mostra a Figura 1. Primeiramente, a pega que permite ao usuário, a partir de empunhadura correta, o manejo do equipamento (1); A haste, que funciona como uma extensão do corpo do usuário e o ajuda na leitura do espaço circundante, por meio de sinais táteis por ela transmitidos ao tocar o solo (2); e a ponteira, responsável pelo contato direto com o solo (3).

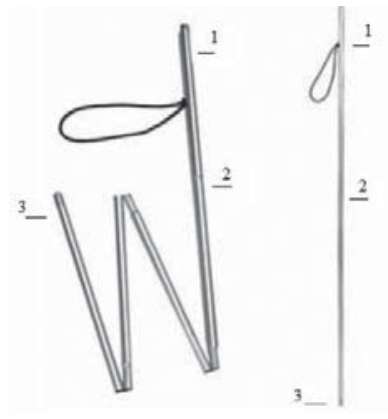

FIGURA 1 - Partes Integrantes da Bengala Longa

FONTE: VIEGAS, 2006.

http://www. bastosviegas.com/medical/detalhe_fot. php?ler $=2829 \&$ cod_cat $=57$
O comprimento total da bengala é definido em função da altura do usuário. O material utilizado geralmente é alumínio ou latão na parte da haste e, sua pega, na maioria dos casos se constitui por algum tipo de forração. Algumas bengalas possuem suas hastes revestidas por pinturas. Outra característica da bengala longa é a possibilidade de optar pela haste articulada, que é interligada por um elástico o que permite o seu recolhimento, diminuindo significativamente suas dimensões. Essa facilidade proporciona maior comodidade, podendo ser guardada dentro de bolsas ou no próprio bolso do usuário quando este se encontrar em locais onde não fará uso do equipamento como, por exemplo, em ambientes fechados com grande aglomeração de pessoas. A outra opção consiste em haste não articulada, sendo ambas, ilustradas na Figura 1.

O uso da bengala longa tradicional inclui algumas técnicas com objetivos específicos, tal como a técnica de toque, que de acordo com Felippe (2001, p. 40) “[...] permite que o cego detecte diferenças de níveis e objetos que se encontram no plano do solo à linha cintura, em ambientes internos e externos, familiares ou desconhecidos [...]". Leva-se em consideração que uma das premissas do projeto bengala longa eletrônica assenta-se na manutenção das técnicas de uso da bengala longa tradicional, em especial a técnica de toque, amplamente utilizada pelo cego, durante seu deslocamento de forma independente em espaço urbano aberto. A referida técnica consiste no uso de um sistema de exploração realizada do espaço com o toque da ponteira da bengala no solo para a transmissão de sensações táteis.

Deve destacar-se neste ponto que de acordo com Dischinger (1999, p..50): “A bengala 
longa, de forma similar ao cão guia, alerta a presença de algumas barreiras físicas. O espaço é percebido através dos sentidos remanescentes, tal como a audição, o olfato e o sentido haptico".

\section{Projeto Bengala Longa Eletrônica}

O projeto Bengala Longa Eletrônica é fruto da união de trabalhos que aconteceram, concomitantemente em pesquisas separadas e em áreas distintas. Uma pesquisa projetou o tipo de sensoriamento necessário, assim como o hardware e software de um aparelho que permitia identificar as barreiras físicas localizadas acima da linha da cintura, contribuindo ao deslocamento de forma segura e independente em espaços urbanos.

Outra pesquisa compôs uma proposta de design conceitual que propunha uma releitura da bengala longa tradicional para deficientes visuais, com intuito de assegurar suas características formais e de uso com a técnica de toque, mas sugerindo que fosse adicionado à sua pega um sistema eletrônico para a identificação das barreiras físicas localizadas acima da linha da cintura.

$\mathrm{Na}$ sequência, foram integrados os esforços com o mesmo objetivo, que era o de desenvolver um protótipo nacional de bengala eletrônica. Esta nova etapa culminou no projeto Bengala Longa Eletrônica, no qual a proposta eletrônica e a proposta de design deram-se as mãos, com o objetivo de apresentar um novo conceito de bengala para deficientes visuais. Essa proposta foi selecionada na chamada pública MCT/Finep - Ação Transversal - Tecnologias Assistivas, em Se- tembro de 2005, com o apoio do MCT, o CNPq e o suporte da Financiadora de Estudos e Projetos (FINEP).

Em 2010, com apoio do ITSBrasil/CNPq, na chamada Apoio a Projetos em Fase Final de Desenvolvimento Tecnológico de Ajudas Técnicas, foi possível aperfeiçoar o protótipo desenvolvido, preparando-o para sua futura produção e distribuição.

\section{Estudos Realizados}

Atualmente, não existe equipamento nacional similar à bengala longa ao alcance da população portadora de deficiência visual no Brasil. Os produtos similares que ajudam no processo de Orientação e Mobilidade do cego são importados e de valor elevado. Cabe salientar também, que outros equipamentos de Tecnologia Assistiva disponíveis no mercado brasileiro que se propõem atender o mesmo problema, na sua maioria, afastam-se da proposta do modelo de bengala longa, descaracterizando o aspecto formal desse instrumento e prevendo o acréscimo de outros objetos, tais como óculos e sapatos, por exemplo.

Como comentado anteriormente, a bengala longa ou de Hoover acompanha os desníveis do piso, mas não pode prever variações localizadas acima da linha da cintura, conforme demonstrado na Figura 2. Isto foi constatado no trabalho pioneiro de Hoyle (2003).

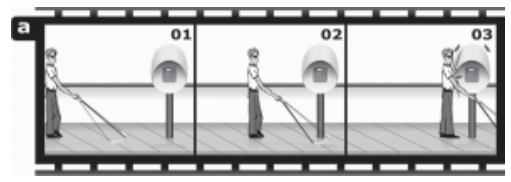

FIGURA 2 - Limitações da Bengala Longa

Elaborado(s) pelo(s) próprio(s) autor(es). 
Neste trabalho, inspirados na tecnologia haptica (MCLAUGHLIN et al., 2002), foi utilizado um sensoriamento ultrassônico que, ao ser processado, possibilita a emissão de uma resposta tátil que sinaliza a presença de barreiras acima da linha da cintura do usuário. Essa resposta é dada em forma de vibração e sons gerados no interior da pega. Na medida em que a bengala se aproxima dos obstáculos a resposta tátil torna-se mais intensa, pulsando cada vez mais rapidamente. Torna-se importante ressaltar que a proposta do projeto busca preservar a estrutura formal e de uso da bengala longa tradicionalmente usada pelos cegos no processo de locomoção.

Cabe ressaltar que o sinal ultrassônico emitido tem alcance aproximado ao da haste do equipamento, enquanto forma um cone de detecção que protege a largura dos ombros. Esta característica procura integrar a informação fornecida pelo sensor às características de uso da bengala longa tradicional, mantendo as técnicas de uso, sobretudo a técnica de toque, mas garantindo uma proteção na presença de obstáculos acima da linha da cintura, Figura 3.

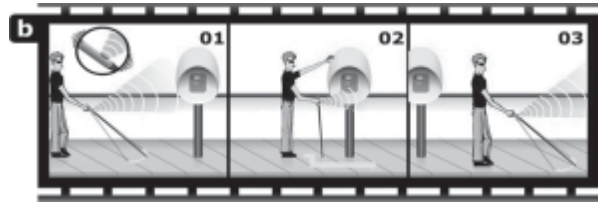

FIGURA 3 - A Nova Bengala Alerta Sobre Obstáculos Acima da Linha da Cintura

Elaborado(s) pelo(s) próprio(s) autor(es).

A opção da resposta tátil (vibração) objetiva não sobrecarregar o sentido da audição, tão importante para o processo de percepção e reconhecimento do espaço. Dessa forma, poderá ser selecionada a resposta como sendo vibração, som ou ambas.

Torna-se importante relatar que o uso de sensor ultrassônico, ao invés de óptico, permitiu sinalizar qualquer tipo de obstáculos, inclusive os translúcidos e transparentes, não contemplados nos sinais a laser, por exemplo.

A configuração formal do equipamento em questão, resultante de um processo de design, possibilitou concentrar a eletrônica do da proposta na pega, sem descaracterizar o aspecto formal e funcional da bengala longa tradicional, já consagrado como estereótipo popular, pelo público usuário, o que possibilitou a indicação da técnica de toque para seu uso. Desta forma, assegurar a similaridade com as características formais e de uso da bengala longa tradicional foi o princípio norteador para o projeto, com o intuito de facilitar a absorção das inovações contidas na proposta pelos deficientes visuais.

\section{Componentes da Nova Bengala}

O novo modelo de bengala, construído em 2006 e aperfeiçoado em 2010, possui as componentes ilustradas na Figura 4, sendo:

(1) Corpo da pega: comporta uma espera para receber a haste da bengala e o sistema eletrônico, assim como uma marcação para o dedo indicador do usuário, de forma a facilitar a pega e a manutenção da posição correta do conjunto. Esta parte do equipamento abriga também parte das aberturas para entrada de ar na sua lateral, aproveitando o próprio movimento da bengala em seu uso para refrigerar os componentes eletrônicos internos durante o seu funcionamento.

(2) Tampa superior: possui a função de concluir 
o diâmetro da pega onde fica disposto o botão de liga/desliga e regulagem da intensidade da resposta tátil. Esta peça também abriga parte das aberturas para entrada de ar na sua lateral assim como o complemento da marcação para o posicionamento correto do dedo indicador do usuário.

(3) Haste com acoplador: tem por finalidade unir a haste ajustada ao tamanho do usuário com a pega, sendo dobrável ou não.

(4) Tampa traseira: tampo vazado que possui a função de facilitar a saída de ar, para contribuir com o processo de resfriamento do sistema eletrônico. Esta peça também é responsável pela união do corpo da pega e sua tampa superior.

(5) Interruptor e potenciômetro: servem para acionar os comandos de liga/desliga e permitem a regulagem da intensidade do sinal tátil, de acordo com a necessidade de cada usuário.

(6) Aberturas de refrigeração: objetiva a entrada de ar, aproveitando o movimento da natural de um lado para o outro com a bengala, estabelecido pela técnica de toque, para refrigeração do sistema eletrônico.

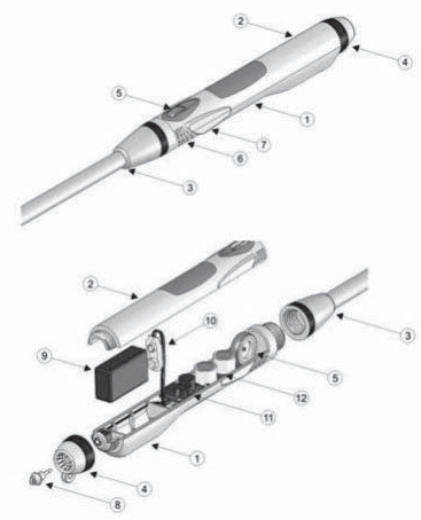

FIGURA 4 - Componentes da Proposta

Elaborado(s) pelo(s) próprio(s) autor(es).

(7) Indicador de posição para o dedo indicador: tem como função principal a manutenção da posição correta do dedo indicador do usuário seguindo a técnica de toque o que conseqüentemente assegura a posição correta do sensor.
(8) Tampa da entrada do carregador de baterias: possui a função de proteger a entrada para recarga da bateria.

(9) Bateria: é responsável pela energia que mantém o funcionamento do sistema eletrônico, proporcionando autonomia de oito horas contínuas de uso.

(10) Conector da bateria: peça responsável pelo elo entre a bateria e os componentes eletrônicos do sistema.

(11) Placa de circuito eletrônico para interpretação e gerenciamento dos dados. Acomoda, em sua parte inferior, o micro-motor responsável pela transmissão da resposta tátil na pega. (12) Sensor: peça responsável pela emissão e recepção do sinal ultrassônico para a detecção das barreiras físicas.

O projeto foi otimizado por uma equipe especializada e posteriormente avaliado por professores de Orientação e Mobilidade e voluntários cegos conhecedores da técnica de toque usando a bengala longa. Posteriormente, foram refinados os aspetos formais e de funcionamento da proposta, considerando os resultados dessa avaliação, resultando no protótipo mostrado na Figura 5.

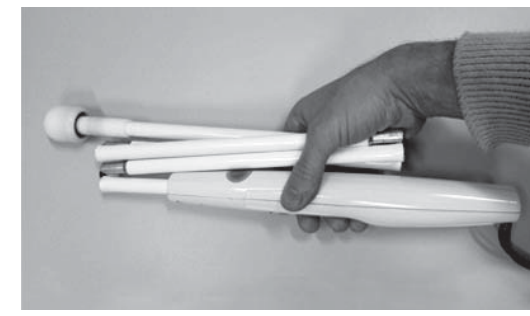

FIGURA 5 - Protótipo Construído em 2010

Elaborado(s) pelo(s) próprio(s) autor(es).

\section{Experimentos}

A pesquisa culminou com a realização de um experimento que objetivou analisar a efi- 
cácia do protótipo desenvolvido com ênfase em sua contribuição no fornecimento de informações sobre o espaço urbano aberto, sobretudo no tocante à identificação das barreiras físicas localizadas acima da linha da cintura. Pautou-se no propósito de auxiliar pessoas adultas que possuem deficiência visual e que mantém seus sentidos remanescentes preservados, no processo de deslocamento independente em espaços urbanos.

O estudo realizado assumiu um caráter descritivo, conforme Yin (2004), tendo em vista que a coleta dos dados foi desenvolvida em etapas, cada uma planejada ao longo da pesquisa, a partir do controle sob eventos comportamentais. Para desenvolvê-la, adotaram-se métodos e técnicas associados a uma abordagem qualitativa, em função do tratamento dispensado aos dados e da preocupação em compreender as relações e comportamentos dos usuários, a partir de passeios acompanhados e entrevistas semiestruturadas.

Assim, foram utilizados quatro métodos. Primeiramente, foi realizado o estudo dos temas pertinentes à pesquisa, a fim de explorar suas inter-relações, aplicando-se o método de análise documental. No segundo momento foram adotados os métodos de visita exploratória, passeio acompanhado e entrevista semi-estruturada, descritos a seguir.

\subsection{Análise Documental}

Essa fase compreendeu os estudos bibliográficos com o objetivo de construir a base teórica para a consolidação do trabalho. Consistiu na realização de leituras e estruturação dos temas associados à pesquisa, tal como acessibilidade no espaço urbano, deficiência visual, percepção ambiental e orientação espacial, arquitetura e design inclusivo - e na abordagem de suas inter-relações.

\subsection{Visita Exploratória}

O método de visita exploratória tem, de acordo com Oliveira (2006, p. 18), “[...] o propósito de efetuar o levantamento das características do espaço onde são realizarão os experimentos, para uma maior compreensão das suas disposições físicas [...]". Convém ressaltar que as visitas exploratórias contribuíram diretamente para a organização dos passeios acompanhados, assim como para as entrevistas. Nas visitas foram empregadas técnicas de medições e registros fotográficos, que serviram para fornecer uma breve descrição dos locais, além da estruturação de mapas sintéticos que contemplaram as características físicas dos ambientes onde foram realizados os passeios acompanhados, incluindo a disposição das barreiras físicas presentes, Figura 6.

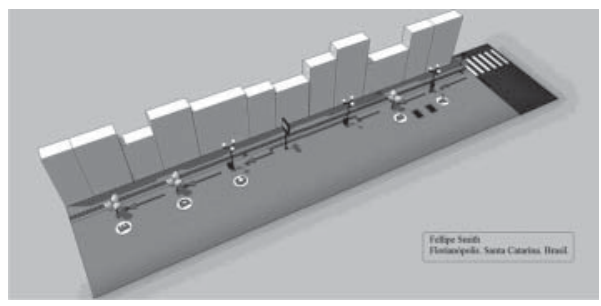

FIGURA 6 - Mapa Sintético de uma Rua de Florianópolis.

Elaborado(s) pelo(s) próprio(s) autor(es). 


\subsection{Passeio Acompanhado}

Com o objetivo de obter informações referentes às dificuldades e facilidades que os cegos enfrentam durante o processo de percepção, orientação e deslocamento de forma independente no espaço urbano foi utilizado o método desenvolvido por Dischinger (2000), denominado passeio acompanhado. Esse método consiste em reiteradas visitas ao local do estudo em companhia dos voluntários, registrando qualquer limitação ou característica relevante à pesquisa. Nesse método, os percursos devem ter um ponto de partida e diversos objetivos a alcançar. O pesquisador deve seguir, sem conduzir ou ajudar, o voluntário durante as atividades.

O processo é registrado pelas técnicas de observação direta, gravação (áudio e vídeo) e fotografia e, ao final, é solicitado ao entrevistado que descreva os aspectos relativos ao passeio. As conversas são gravadas e transcritas e os assuntos, separados por temas. Os eventos significativos são fotografados e localizados espacialmente em mapas sintéticos, como visto na Figura 6. É importante ressaltar que esse método permite acompanhar a dinâmica que se estabelece no cenário proposto, em tempo real, por meio da observação direta e verbalização das experiências vividas e relatadas pelos entrevistados, proporcionando ao pesquisador as respostas a problemas de situações complexas vividas pelo usuário no ambiente estudado. No caso específico deste trabalho, buscou-se compreender questões relacionadas ao processo de percepção, orientação e deslocamento de forma independente no espaço urbano aberto, fazendo uso da Bengala Longa Eletrônica no tocante à identificação das barreiras físi- cas localizadas acima da cintura, encontradas no espaço em estudo.

Um dos primeiros problemas a resolver foi definir o número de voluntários que participaria da experiência. Em Yin (2009), se estabelece que o número ótimo de participantes depende de diversos fatores, tal como os recursos disponíveis, o cronograma e a disponibilidade. Nesta pesquisa foram utilizados oito voluntários para a realização dos testes e dois professores de Orientação e Mobilidade, considerando essas premissas. Os voluntários foram homens cegos com idades entre 21 e 52 anos, com os sentidos remanescentes preservados e conhecedores da técnica de toque.

Nos experimentos foi observado o uso correto da bengala, assim como o funcionamento da detecção e sinalização de obstáculos acima da linha da cintura, a partir das condições impostas pelos espaços selecionados, especialmente, em relação à existência de barreiras físicas.

Tal como foi mencionado, os percursos tinham um ponto de partida e diversas metas a alcançar. A rota era detida apenas quando uma vibração na pega era percebida. Nesse caso, as formas do obstáculo eram reconhecidas, através do toque exploratório, desviando-se o voluntário do obstáculo e retomando a rota original.

\subsection{Entrevista Semi-Estruturada}

A entrevista semiestruturada, de acordo com Preece et al. (2005, p.231), “[...] permite que o entrevistador conte com um roteiro básico para guiar-se, assegurando, dessa forma, que os mesmos tópicos serão abordados pelos diferentes entrevistados [...]". 
O objetivo principal das entrevistas foi basicamente coletar a opinião dos participantes do experimento a respeito do protótipo desenvolvido durante o cumprimento das rotas dos passeios acompanhados, particularmente, sobre sua contribuição no uso, como Tecnologia Assistiva, para o auxílio na identificação, reconhecimento e desvio das barreiras físicas localizadas acima da linha da cintura. A Figuras 7 e a Figura 8 ilustram exemplos de barreiras, com ausência de qualquer tipo de sinalização, encontradas nos passeios acompanhados.

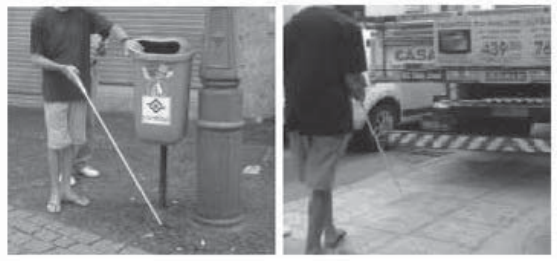

FIGURA 7 - Barreiras Físicas

Elaborado(s) pelo(s) próprio(s) autor(es).

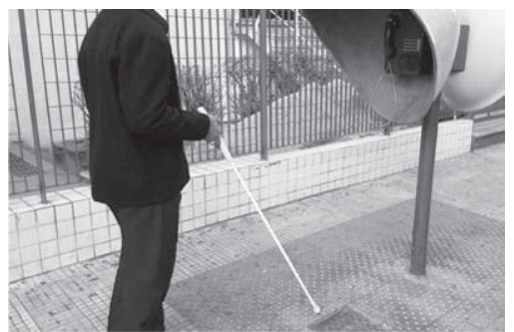

FIGURA 8 - Uma das Principais Fontes de Colisão: o telefone público

Elaborado(s) pelo(s) próprio(s) autor(es).

Cabe destacar que os experimentos foram realizados durante três meses em diferentes horários do dia, assim como na presença de diferentes condições climáticas de modo a verificar a possível existência de fontes de interferências.
O Quadro 1 resume os dados coletados nas entrevistas com os voluntários cegos e o Quadro 2 resume as opiniões dos professores de Orientação e Mobilidade que participaram da experiência. Foram avaliadas a ergonomia, a satisfação e a qualidade dos dados e da informação espacial fornecida pelo aparelho, assim como sua possível contribuição se for inserido nos programas de Orientação e Mobilidade. Os valores contemplados são Sim-Não, Positivo - Negativo - Não definido. A partir da análise dos quadros pode ser concluído que tanto a detecção de obstáculos, quanto a contribuição ao deslocamento seguro foram avaliados satisfatoriamente.

QUADRO 1 - Voluntários Cegos: resumo das entrevistas

\begin{tabular}{|c|c|c|}
\hline No. & Item avaliado & $\begin{array}{c}\text { Resultado Qualitati- } \\
\text { vo (oito voluntários) }\end{array}$ \\
\hline 1 & $\begin{array}{c}\text { Satisfação relacionada ao } \\
\text { uso do dispositivo e suas } \\
\text { funções. }\end{array}$ & Positiva (8) \\
\hline 2 & $\begin{array}{c}\text { Satisfação relacionada } \\
\text { ao projeto ergonômico e } \\
\text { dimensões. }\end{array}$ & Positiva (8) \\
\hline 3 & É de fácil aprendizado? & Sim (6) \\
\hline 4 & $\begin{array}{c}\text { O dispositivo contribuiu } \\
\text { a uma melhor percepção } \\
\text { espacial? }\end{array}$ & Sim (8) \\
\hline
\end{tabular}

Elaborado(s) pelo(s) próprio(s) autor(es).

QUADRO 2 - Professores: resumo das entrevistas

\begin{tabular}{|c|c|c|}
\hline No. & Item avaliado & $\begin{array}{c}\text { Resultado Qua- } \\
\text { litativo (dois } \\
\text { professores) }\end{array}$ \\
\hline 1 & $\begin{array}{c}\text { Precisão, relacionada à detecção } \\
\text { de obstáculos acima da linha da } \\
\text { cintura. }\end{array}$ & Positiva (2) \\
\hline 2 & $\begin{array}{c}\text { Possui uma aparência e ergono- } \\
\text { mia adequadas à aplicação? }\end{array}$ & Sim (2) \\
\hline 4 & $\begin{array}{c}\text { O dispositivo contribuiu a uma } \\
\text { melhor percepção espacial? }\end{array}$ & Sim (2) \\
\hline 3 & $\begin{array}{c}\text { Poderia ser usado nos progra- } \\
\text { mas de Orientação e Mobilidade? }\end{array}$ & Sim (2) \\
\hline 5 & $\begin{array}{c}\text { Competitividade em relação aos } \\
\text { modelos importados? }\end{array}$ & Positiva (2) \\
\hline
\end{tabular}

Elaborado(s) pelo(s) próprio(s) autor(es). 


\section{Futuras Direções da Pesquisa}

Considera-se que o estudo aqui apresentado não está esgotado, abrindo espaço para o desdobramento de novas pesquisas. Nesse sentido, cabe registrar algumas recomendações para futuros trabalhos que pretendam abordar a contribuição de novas propostas de Tecnologia Assistiva para obtenção de informações positivas sobre os espaços urbanos. Uma sugestão seria o estudo da possível contribuição da proposta aqui apresentada no processo de construção, pelos deficientes visuais, de mapas mentais dos espaços urbanos abertos.

Também, o aprofundamento da pesquisa relacionada às contribuições do projeto no ensino das técnicas de Orientação e Mobilidade, considerando que os professores entrevistados confirmam a relevância da referida proposta para a identificação de barreiras que possam tornar-se referências para o entendimento do espaço urbano. Nesse sentido, a ampliação do público-alvo do estudo, na perspectiva de contemplar, com o experimento, deficientes visuais que não apresentem os sentidos remanescentes preservados, além de adolescentes e crianças.

Pensamos que a utilização da metodologia empregada neste trabalho possa ser útil para estruturar novas propostas de experimentos com outros produtos de Tecnologia Assistiva, destinados à obtenção de informações positivas dos espaços urbanos abertos para pessoas portadoras de deficiência.

\section{Conclusões}

A promoção de acessibilidade em espaços urbanos é complexa e exige um profundo entendimento da diversidade do público que os compõe e suas necessidades específicas. Apesar da quantidade significativa de dispositivos legais que garantem o direito à igualdade entre os cidadãos e a implantação de critérios de acessibilidade aos espaços urbanos, ainda nos deparamos, no mundo atual, com uma realidade composta por uma grande distância entre as conquistas legalmente instituídas através de leis, decretos e normas técnicas específicas para o assunto e as ações necessárias para concretizá-las. É nesse ambiente que vivem os portadores de deficiência os quais, tal como qualquer cidadão, possuem o direito de frequentar e desfrutar, de forma independente, com conforto e segurança, dos mais diversos locais, sobretudo nos espaços públicos.

Em particular, assegurar a mobilidade segura para os portadores de deficiência visual, notadamente nos espaços urbanos públicos, é de fundamental importância para a sua participação ativa na sociedade. Tarefas aparentemente simples para as pessoas que dispõem da visão, tal como desviar-se de um carro estacionado sobre a calçada, tornamse um grande problema para o cego, principalmente em função da dificuldade que eles encontram em obter informações não visuais confiáveis dos espaços para o seu processo de orientação e mobilidade. Dessa forma, todos os esforços no sentido de criar dispositivos que contribuam para o fornecimento de informações sobre o espaço urbano são 
extremamente importantes. Foi nessa direção que a presente pesquisa se concentrou, tendo como objetivo principal desenvolver e verificar a contribuição do projeto de Tecnologia Assistiva Bengala Longa Eletrônica na ampliação das possibilidades de fornecimento de informações sobre o espaço urbano aberto, especificamente sobre a presença de barreiras físicas localizadas acima da linha da cintura, que tanto interferem no processo de Orientação e Mobilidade dos cegos e deficientes visuais.

Em particular, o protótipo se mostrou eficaz nos testes realizados ao detectar, com auxilio da eletrônica embarcada, os diversos tipos de barreiras físicas, dispostas nos espaços selecionados para o experimento. Acreditamos que seu uso, aliado às soluções arquitetônicas e urbanísticas, colaborará para o fornecimento de informações importantes para o processo de orientação e mobilidade nesses espaços. As opiniões dos voluntários que participaram da experiência demonstraram sua satisfação quanto aos resultados alcançados. Os cegos e professores verbalizaram a experiência como sendo positiva, afirmando a importância do projeto como instrumento colaborador para obtenção de informações positivas sobre o espaço urbano aberto, sobretudo em relação às barreiras físicas localizadas acima da linha da cintura. A possibilidade de identificar as barreiras foi apontada como benéfica para a orientação espacial durante o deslocamento no espaço urbano, tornando-se um referencial de identificação e não apenas uma barreira a ser transposta.

Outro fator importante constatado consistiu na confirmação da idéia de manter as características formais e de uso da bengala longa tradicional, integradas ao ensino de Orientação e Mobilidade e suas técnicas específicas. Foi também salientada pelos voluntários a importância das informações táteis (vibração) percebidas com o uso do sensor ultrassônico, que possibilitam interação com outros canais sensitivos. Também os professores de Orientação e Mobilidade mostraram opiniões favoráveis à proposta do projeto destacando sua importância como instrumento colaborador para obtenção de informações sobre os espaços urbanos no contexto do ensino das técnicas dessa disciplina.

Conclui-se que a combinação da tecnologia proposta e dos instrumentos metodológicos apresentados permitiu a compreensão de uma nova e possível forma integrada de promover acesso a informações positivas sobre o espaço urbano às pessoas que possuem algum tipo de deficiência visual. Por meio do uso de tecnologias atuais, aplicadas na estruturação de uma proposta de Tecnologia Assistiva, pretende-se apontar para novas perspectivas no sentido de ampliar a participação ativa na sociedade, contribuindo para assegurar o direito de deslocamento de forma independente, proporcionando diálogos com a complexidade dos espaços públicos e colaborando para a inclusão social.

Cabe destacar que no País são conhecidos apenas dois modelos, ambos importados, de elevado valor, dificultando sua aquisição.

A invenção foi depositada em Brasil e aguarda o parecer técnico relativo ao pedido de exame. Destaca-se também que os testes e validações realizadas foram registrados e aprovados pelo comitê ético da Universidade Federal de Santa Catarina. 


\section{Agradecimentos}

Agradecemos à FINEP e ao ITSBrasil pela parceria e apoio financeiro nas diversas etapas de pesquisa e desenvolvimento.

\section{Referências}

DISCHINGER, M. Designing for all senses: accessible spaces for visually impaired citizens. 2000. Dissertation (Doctoral) - Department of Space and Process School of Architecture, Chalmers University of Technology, 2000, Sweden.

DISCHINGER, M.; ELY, V.H.M.B. A I mportância dos Processos Perceptivos na Cognição de Espaços Urbanos para Portadores de Deficiência Visual. In: IX CONGRESSO BRASILEIRO DE ERGONOMIA, 9., 1999, Salvador. [Anais]. Salvador: [s.n.], 1999. p. 1-8.

FELIPPE, J.A. de M. Caminhando J untos: manual das habilidades básicas de Orientação e Mobilidade. São Paulo: Laramara - Associação Brasileira de Assistência ao Deficiente Visual, 2001.

FELI PPE, J.A. de M.; FELI PPE, V.L.L.R. Orientação e Mobilidade. São Paulo: Laramara - Associação Brasileira de Assistência ao Deficiente Visual, 1997.

GARCI A, N. Como Desenvolver Programas de Orientação e Mobilidade Para Pessoas com Deficiência Visual. In: BRASIL. Ministério de Educação e Cultura. Secretaria de Educação Especial. Orientação e Mobilidade: conhecimentos básicos para a inclusão do deficiente visual. Brasília, 2003. p. 68-121.

HOFFMANN, S.B.; SEEWALD, R. Caminhar sem Medo e sem Mito: orientação e mobilidade. 2009. Disponível em: <http://www. bengalalegal.com> Acesso em: 10 de Dezembro de 2012.

HOYLE, B. S. The Batcane- mobility aid for the vision impaired and the blind. In: Proc. of IEE Symposium on Assistive Technology, 18-22, 2003. p. 18-23.

MCLAUGHLIN, M.L. et al. (Ed.). Touch in virtual environments: haptics and the design of interactive systems. New Jersey, California: Prentice Hall. 2002. 
OLIVEIRA, A.S.D.A de. Acessibilidade Espacial em Centro Cultural: estudos de caso. 2006. Dissertação (Mestrado) - Programa de Pós-Graduação em Arquitetura e Urbanismo, Universidade Federal de Santa Catarina, 2006, Florianópolis, BR-SC.

PREECE, J. et al. Interaction design: beyond human-computer. New York: J ohn Wiley \& Sons. 2005.

SOCIEDADE DE ASSISTÊNCIA AOS CEGOS-SAC. Orientação e Mobilidade. Disponível em: <http://www. sac.org.br>. Acessado em: $10 \mathrm{dez}$. 2012. Não paginado.

YIN, R.K. Case study research: design and methods. Thousand Oaks, CA: Sage Publ., 2009. (Applied Social Research Methods Series, v. 5)

Submetido para avaliação em 26 jul.2011. Aprovado para publicação em 02 ago.2012.

\section{Renato Fonseca Livramento da Silva}

Universidade da Paraíba. João Pessoa/PR, Brasil. E-mail: fonsilva3@hotmail.com.

\section{Alejandro Rafael Garcia Ramirez}

Universidade do Vale do Itajaí. Itajaí/SC, Brasil. E-mail: ramirez@univali.br 